\title{
Dynamics of Respiration during Rapid Rate Mechanical Ventilation in Anesthetized and Paralyzed Rabbits
}

\author{
J. JULIO PÉREZ FONTÁN, GREGORY P. HELDT, AND GEORGE A. GREGORY \\ Cardiovascular Research Institute and the Departments of Pediatrics and Anesthesia, University of California, \\ San Francisco, California
}

\begin{abstract}
Infants with respiratory failure are often ventilated at rates exceeding $60 \mathrm{breath} \cdot \mathrm{min}^{-1}$. To obtain insight into the factors controlling the delivery and distribution of tidal volume at these ventilatory rates, we analyzed the inspiratory and expiratory pressure-flow relationships of the respiratory system and its components (lungs, endotracheal tube, and chest wall) in anesthetized, paralyzed rabbits ventilated at 60,90 , and 120 breath $\cdot \min ^{-1}$. Inspiratory times were $0.3,0.2$, and $0.1 \mathrm{~s}$. Driving pressure was maintained constant. We expressed the effect of ventilatory rate and flow direction on the pressure-flow relationships as changes in compliance, mean resistance, and inertance. We found a nonlinear pressure-flow relationship in both endotracheal tube and respiratory system. This nonlinearity could be accurately described as a function of gas flow and volume acceleration with similar coefficients for tube and respiratory system. Although the inspiratory and expiratory compliance and the mean inspiratory resistance of the lungs were lower at the higher ventilatory rates, the constant resistive behavior of the endotracheal tube and the constant elastic behavior of the chest wall caused a relatively rate-independent pressure-flow behavior of the respiratory system. The lower inspiratory resistance of the lungs was offset by the higher inspiratory resistance of the endotracheal tube, resulting in the resistance of the respiratory system being independent of the direction of gas flow. The rate-dependency of compliance and inspiratory resistance of the lungs suggests an heterogeneous distribution of inspiratory flow at rapid ventilatory rates. At these ventilatory rates, the high resistance of the respiratory system and the nonlinearity of the pressure-flow relationship decrease the tidal volume delivered to the lungs in a magnitude that can be predicted from the time course of the ventilatory pressure. (Pediatr Res 20: $750-755,1986)$
\end{abstract}

\section{Abbreviations}

PEEP, positive end-expiratory pressure FRC, functional residual capacity ANOVA, analysis of variance

The effect of ventilatory rate on the delivery and distribution of gas flow in the respiratory system is often inferred from

Received November 15, 1985; accepted March 24, 1986.

Address for correspondence and reprints J. Julio Pérez Fontán, M.D., Assistant Professor of Pediatrics, Yale University Medical School, Department of Pediatrics, Division of Critical Care and Applied Physiology, 333 Cedar Street, New Haven, CT 06510 .

This work was supported in part by SCOR Grant HL-27356 from the National Heart, Lung and Blood Institute. pressure-flow relationships and expressed as changes in compliance, resistance, and inertance (1-7). Analyses using this approach have customarily relied on two assumptions: first, that the pressure-flow relationships in the respiratory system are linear, and second, that the pressure waveform applied to the respiratory system is sinusoidal. However, the validity of these assumptions as applied to the mechanically ventilated infant may be questioned: the first because of the nonlinear pressureflow behavior of the endotracheal tube (8), and the second because a longer expiratory than inspiratory time is necessary to avoid gas trapping in the lungs as ventilatory rate is increased.

In this study, we analyzed the effects of rapid rate mechanical ventilation [as commonly applied to infants with respiratory failure (9)] on the pressure-flow behavior of the respiratory system and its components: endotracheal tube, lungs, and chest wall. We examined how these components interact to affect tidal volume and its distribution at rapid ventilatory rates in anesthetized and paralyzed rabbits. Unlike previous studies $(1-3,6,7)$, our analysis takes into account both the nonlinearities of the pressure-flow relationship and the differences between inspiration and expiration.

\section{METHODS}

Preparation. Ten New Zealand White rabbits weighing 2.50 $3.41 \mathrm{~kg}(2.94 \pm 0.30 \mathrm{~kg}$, mean $\pm \mathrm{SD})$ were anesthetized with halothane and placed in the supine position. The marginal vein of the ear was cannulated for fluid and drug administration, and a tracheostomy was performed below the first tracheal cartilage. Through the tracheostomy, we introduced an endotracheal tube and a catheter for pressure measurement, which were enclosed by a stainless steel tube of $0.55 \mathrm{~cm}$ of external diameter and 2 $\mathrm{cm}$ of length (Fig. 1). The endotracheal tube (Portex, Inc., Wilmington, MA) had an internal diameter of $0.3 \mathrm{~cm}$ and was $16.5 \mathrm{~cm}$ long. The catheter for pressure measurement was made of a length of PE-160 tubing and had four side holes within 1 $\mathrm{cm}$ of its occluded end. Gas leaks were prevented by placing a tie around the trachea and by filling the space between the endotracheal tube, the catheter, and the inner wall of the stainless steel tube with silicon rubber. The stainless steel tube prevented the tie around the trachea from compressing the endotracheal tube and the catheter, thereby preserving their dynamic response. In addition, the stainless steel tube maintained the relative positions of the endotracheal tube, the tracheal catheter, and the trachea. Given the distance between the lateral holes of the tracheal catheter and the tip of the endotracheal tube $(3 \mathrm{~cm})$, the tracheal diameter of the rabbits (average $=0.55 \mathrm{~cm}$ ), and the Reynolds number of the tracheal flow, the error in the measurement of tracheal pressure caused by the Bernoulli effect would not have exceeded $3 \%$, even at peak flows (10).

A double lumen polyethylene catheter $(0.22 \mathrm{~cm}$ of external diameter) was inserted in the right pleural space through a small 


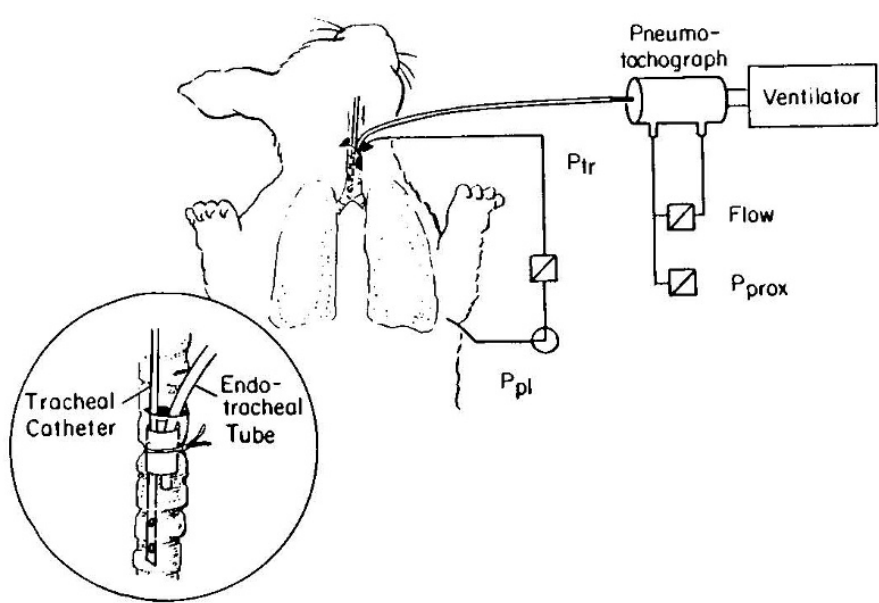

Fig. 1. Experimental preparation. $P_{t r}=$ tracheal pressure. $P_{p l}=$ pleural pressure. $P_{\text {prox }}=$ pressure measured proximal to the endotracheal tube. Inset, detail of the insertion of the endotracheal tube and tracheal catheter in the trachea.

thoracotomy. The first lumen of the catheter opened to an end hole, which was used to evacuate the pneumothorax produced during the insertion of the catheter. The second lumen connected a latex balloon $(1 \times 3 \mathrm{~cm})$ to one side of a differential pressure transducer (Celesco Model LCVR, $\pm 50 \mathrm{~cm} \mathrm{H} \mathrm{H}_{2} \mathrm{O}$, Canoga Park, $\mathrm{CA}$ ) for measurement of pleural pressure. The other side of this differential pressure transducer was attached to the tracheal catheter by a three-way stopcock, which allowed us to measure both transpulmonary (from the trachea to the pleural space) and tracheal pressure. The pleural balloon had a flat pressure-volume relationship for volumes of $0.5-1.2 \mathrm{ml}$ and was inflated to 0.75 $\mathrm{ml}$ during the experiment. The position of the balloon was adjusted during airway occlusions at the beginning of an inspiration using the method of Baydur et al. (11).

A Fleisch no. 00 pneumotachograph was inserted between the connector of the endotracheal tube and the circuit of a constantflow, time-cycled infant ventilator (Healthdyne Model 105, Marietta, GA) for measurement of gas flow. The arms of the pneumotachograph were connected to a differential pressure transducer (Celesco Model LCVR, $\pm 2 \mathrm{~cm} \mathrm{H}_{2} \mathrm{O}$ ) with low-compliance tubing. The output of the pneumotachograph was calibrated with a rotameter, and was linear and symmetrical for inspiratory and expiratory flows up to $150 \mathrm{ml} \cdot \mathrm{s}^{-1}$. The proximal arm of the pneumotachograph was also connected via a lateral port to a pressure transducer (Validyne Model MP-45-1, $\pm 100 \mathrm{~cm} \mathrm{H}_{2} \mathrm{O}$, Northridge, CA) for measurement of pressure proximal to the endotracheal tube. We adjusted the length of the tubing connecting the pressure transducers to the tracheal and pleural catheters and to the pneumotachograph so that the output of the transducers was zero when pressure and flow measuring systems were enclosed in a sealed plastic box. The box was pressurized with a syringe pump to frequencies up to $5 \mathrm{~Hz}$. The stroke volume of the pump was adjusted to create pressures in the box similar to those measured in the airway during the experiment. The amplitude-frequency responses of the pressure and flow measuring systems were estimated to be flat to frequencies greater than $20 \mathrm{~Hz}$ from their response to a step change in pressure or flow. The step change in pressure was created by the explosion of a rubber balloon. The step change of flow was produced by the sudden interruption of gas flow with a solenoid valve (closing time $<0.004 \mathrm{~s}$ ).

Once preparations were complete, halothane anesthesia was discontinued and $20 \mathrm{mg} \cdot \mathrm{kg}^{-1}$ of pentobarbital and $0.2 \mathrm{mg} \cdot \mathrm{kg}^{-1}$ of pancuronium bromide were injected intravenously as needed to sedate and paralyze the rabbits. Each rabbit received a continuous infusion of $6 \mathrm{ml} \cdot \mathrm{kg}^{-1} \cdot \mathrm{h}^{-1}$ of normal saline or Ringer's lactate. Its rectal temperature was kept constant at $38.5 \pm 1^{\circ} \mathrm{C}$ with a servo-controlled radiant warmer.
The signals of pressure and flow were amplified, digitized at a sampling rate of $100 \mathrm{~Hz}$, displayed on a video monitor, and stored for analysis with a computerized data acquisition system.

Protocol. To study the effects of rapid ventilatory rates on the pressure-flow behavior of the respiratory system, each rabbit was ventilated at 60,90 , and 120 breath $\cdot \mathrm{min}^{-1}$ in a random order. The inspiratory time was set at $0.3,0.2$, and $0.1 \mathrm{~s}$, respectively. (Actual measured inspiratory times were $0.33,0.22$, and $0.13 \mathrm{~s}$.) Peak-inspiratory pressure and PEEP were 14 and $2 \mathrm{~cm} \mathrm{H}_{2} \mathrm{O}$. The inspired fractional concentration of oxygen was 1.0 . We adjusted the constant flow through the ventilator circuit to 10,20 , and 30 liter $\cdot \min ^{-1}$ at ventilatory rates of 60,90 , and 120 breath $\cdot \min ^{-1}$, to maintain a constant mean airway pressure of $5 \mathrm{~cm} \mathrm{H}_{2} \mathrm{O}$ (calculated as the quotient of the time integral of the pressure proximal to the endotracheal tube and the duration of the breath). Mean tracheal pressure and mean transpulmonary pressure were also constant at $4.2 \pm 0.5$ and $3.5 \pm 0.4 \mathrm{~cm} \mathrm{H} \mathrm{H}_{2} \mathrm{O}$, respectively. Therefore, we expected the mean volume of the lungs to be constant at different ventilatory rates, and independent of tidal volume. Gas trapping due to an insufficient expiratory time was ruled out at all ventilatory rates by demonstrating the return of the flow signal to the baseline at the end of every expiration.

At each ventilatory rate, the rabbit's lungs were inflated three times for $2 \mathrm{~s}$ with a pressure of $25 \mathrm{~cm} \mathrm{H}_{2} \mathrm{O}$ to provide a consistent lung volume history. Then, following a 10 -min equilibration period, we measured pressures and gas flow. In five of the rabbits we also measured the FRC of the lungs by triplicate helium equilibrations (12).

Analysis. The effective compliance (C), resistance (represented by the two Rohrer constants, $\mathrm{K}_{1}$ and $\mathrm{K}_{2}$ ), and inertial coefficient (I) of the respiratory system or lungs alone were calculated by fitting the changes in pressure $(\Delta \mathrm{P})$, proximal to the tube or transpulmonary, to the equation of motion of the respiratory system:

$$
\Delta \mathrm{P}=\Delta \mathrm{V} / \mathrm{C}+\mathrm{K}_{1} \cdot \dot{\mathrm{V}}+\mathrm{K}_{2} \cdot \dot{\mathrm{V}}^{2}+\mathrm{I} \cdot \ddot{\mathrm{V}}
$$

with a multiple linear regression $(13,14)$. In this equation, $\Delta \mathrm{V}$ represents the change in lung volume (obtained by digital integration of the flow), $\dot{V}$ the gas flow across the endotracheal tube $(\mathrm{dV} / \mathrm{dt})$, and $\mathrm{V}$ the volume acceleration of the gas $\left(\mathrm{d}^{2} \mathrm{~V} / \mathrm{dt}^{2}\right)$. The resistance of the endotracheal tube was determined by fitting the pressure difference across the tube (calculated as the difference between the pressure proximal to the endotracheal tube and the tracheal pressure) to a similar equation in which the elastic term $(\Delta \mathrm{V} / \mathrm{C})$ was eliminated (8). The compliance of the chest wall $\left(\mathrm{C}_{\mathrm{W}}\right)$ was calculated from the compliances of the respiratory system $\left(\mathrm{C}_{\mathrm{RS}}\right)$ and lungs $\left(\mathrm{C}_{\mathrm{L}}\right)$ as:

$$
\mathrm{C}_{\mathrm{W}}=\left(\mathrm{C}_{\mathrm{L}} \cdot \mathrm{C}_{\mathrm{RS}}\right) /\left(\mathrm{C}_{\mathrm{L}}-\mathrm{C}_{\mathrm{RS}}\right)
$$

assuming that chest wall and lungs were dynamically in series (15). Eight breaths were analyzed for each ventilatory rate. The coefficient of variability between breaths was less than $5 \%$ for the compliance, and less than $10 \%$ for $\mathrm{K}_{1}, \mathrm{~K}_{2}$, and I.

This method of analysis permits the separate calculation of inspiratory and expiratory compliances, resistances, and inertial coefficients. By expressing the resistance as a function of gas flow $\left(\mathrm{R}=\mathrm{K}_{1}+\mathrm{K}_{2} \cdot \dot{\mathrm{V}}\right)$, it also takes into account any nonlinearity of the pressure-flow relationship caused by frictional pressure losses in phase with gas flow. The method assumes, however, that compliance is constant within the range of tidal volume. To validate this assumption, we determined the static pressurevolume relationship of the respiratory system of six of the rabbits by performing airway occlusions at different lung volumes. The rabbits' lungs were ventilated for this test at a ventilatory rate of 60 breath $\cdot \mathrm{min}^{-1}$, with tidal volumes of $10-12 \mathrm{ml} \cdot \mathrm{kg}^{-1}$, and PEEP of $2 \mathrm{~cm} \mathrm{H}_{2} \mathrm{O}$. The static pressure-volume relationship was linear in all six rabbits (Fig. 2), even when the lung volume was greater than those used in the experiment.

Resistances were expressed as a function of gas flow, and thus 

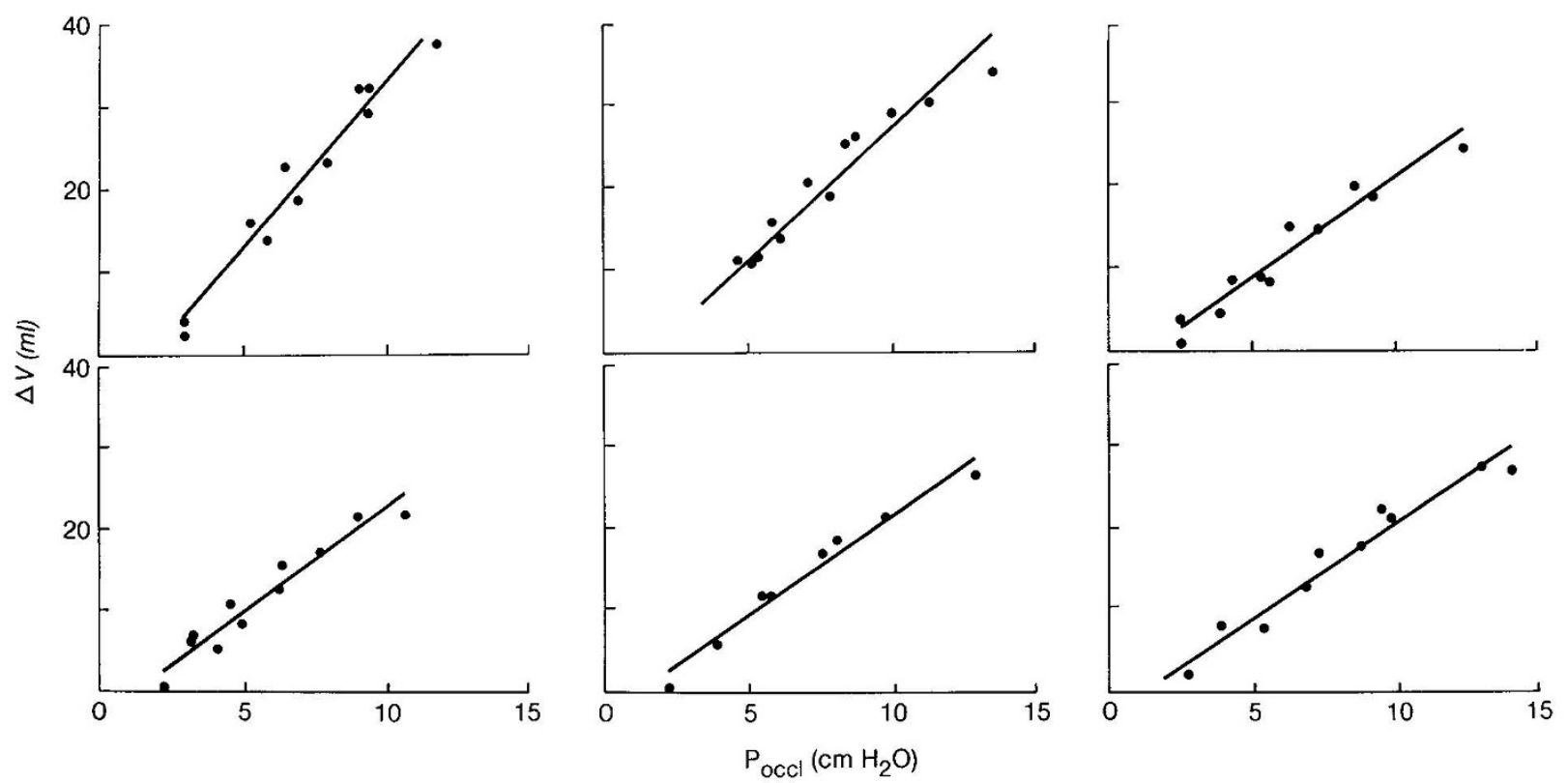

Fig. 2. Static pressure-volume relationships in six rabbits in which airway occlusions were performed at different points in the ventilatory cycle. Note that the tidal volumes during the occlusions were greater than during the experiment. The occlusion pressure $\left(\mathrm{P}_{\text {occl }}\right)$ correlated linearly with the changes in lung volume $(\Delta \mathrm{V})$, indicating that the static compliance of the respiratory system was constant within the range of the tidal volume.

they cannot be described with a flow-independent constant. Therefore, we calculated a mean resistance $(\overline{\mathrm{R}})$ using the following expression:

$$
\overline{\mathrm{R}}=\mathrm{K}_{1}+\mathrm{K}_{2} \overline{\mathrm{V}}
$$

where $\overline{\mathrm{V}}$ represents the mean flow across the endotracheal tube, computed as the quotient of the time integral of the flow and the inspiratory or expiratory time.

Compliances, resistances, and inertial coefficients were compared for differences between inspiration and expiration with a two-factor ANOVA with replication (16). Inspiratory and expiratory values were analyzed separately for differences caused by ventilatory rate with a single factor ANOVA with replication. Lung volumes, gas flows, and pressures were also analyzed with a single factor ANOVA with replication. A posteriori analysis was performed with the Newman-Keuls test (16). All values are presented as mean values $\pm 1 \mathrm{SD} . p$ values of less than 0.05 were considered significant.

\section{RESULTS}

The pressure-flow relationships of the respiratory system, endotracheal tube, and lungs were defined accurately with equation 1 . The residual mean squared error of the multiple linear regression was less than 0.1 and $0.2\left(\mathrm{~cm} \mathrm{H}_{2} \mathrm{O}\right)^{2}$ for inspiratory and expiratory data, respectively.

The respiratory system and endotracheal tube exhibited a similarly nonlinear pressure-flow relationship. The major component of this nonlinearity was in phase with gas flow (Fig. 3). In our analysis, flow-related nonlinearity of the pressure-flow relationship was characterized by the value of $K_{2}$. This value was independent of ventilatory rate and lower during inspiration than during expiration for both the respiratory system and the endotracheal tube (Table 1). The value of $\mathrm{K}_{2}$ of the lungs, however, was not statistically different from zero in most rabbits $(t$ test), suggesting that the pressure-flow behavior of the lungs was linear.

The effective inspiratory and expiratory compliances of the lungs and the respiratory system were lower at the higher ventilatory rates (Table 2). The chest wall compliance was independent of the ventilatory rate, causing the compliance of the respi- ratory system to be less rate-dependent than the compliance of the lungs alone.

The mean resistance of the lungs decreased at the higher ventilatory rates during inspiration. This decrease was offset, however, by a small increase in the mean resistance of the endotracheal tube. Consequently, the mean inspiratory resistance of the respiratory system was independent of ventilatory rate. All mean resistances were independent of ventilatory rate during expiration.

The mean inspiratory resistance of the lungs was $39-18 \%$ of the mean expiratory resistance, depending on ventilatory rate. The mean resistance of the endotracheal tube was higher during inspiration, primarily because of the higher mean inspiratory flows. The higher mean inspiratory resistance of the tube offset the lower mean inspiratory resistance of the lungs and caused the mean resistance of the respiratory system to be similar during inspiration and expiration.

Tidal volume decreased in proportion to inspiratory time (Table 3). Mean inspiratory and expiratory flows were, therefore, independent of ventilatory rate (except for the mean expiratory flow at a ventilatory rate of $120 \mathrm{breath} \cdot \mathrm{min}^{-1}$ ). This circumstance made it possible to compare mean resistances without taking into account differences in mean gas flow caused by ventilatory rate.

The inertial coefficients (I) of respiratory system, lungs alone, and endotracheal tube averaged $0.41,0.06$, and $0.30 \cdot 10^{-3} \mathrm{~cm}$ $\mathrm{H}_{2} \mathrm{O} \cdot \mathrm{ml}^{-1} \cdot \mathrm{s}^{2}$, respectively, and were independent of ventilatory rate and the direction of flow.

\section{DISCUSSION}

Our results show that, through the interaction of the endotracheal tube, lungs, and chest wall, the overall pressure-flow behavior of the respiratory system of mechanically ventilated rabbits is nonlinear and relatively independent of ventilatory rate and flow direction. In contrast, the pressure-flow behavior of the lungs alone is substantially affected by ventilatory rate and flow direction, as indicated by the decrease of pulmonary compliance and resistance at the higher rates and by the difference between inspiratory and expiratory resistances. The pulmonary mechanics, lung volumes, and tracheal diameter of adult rabbits approx- 

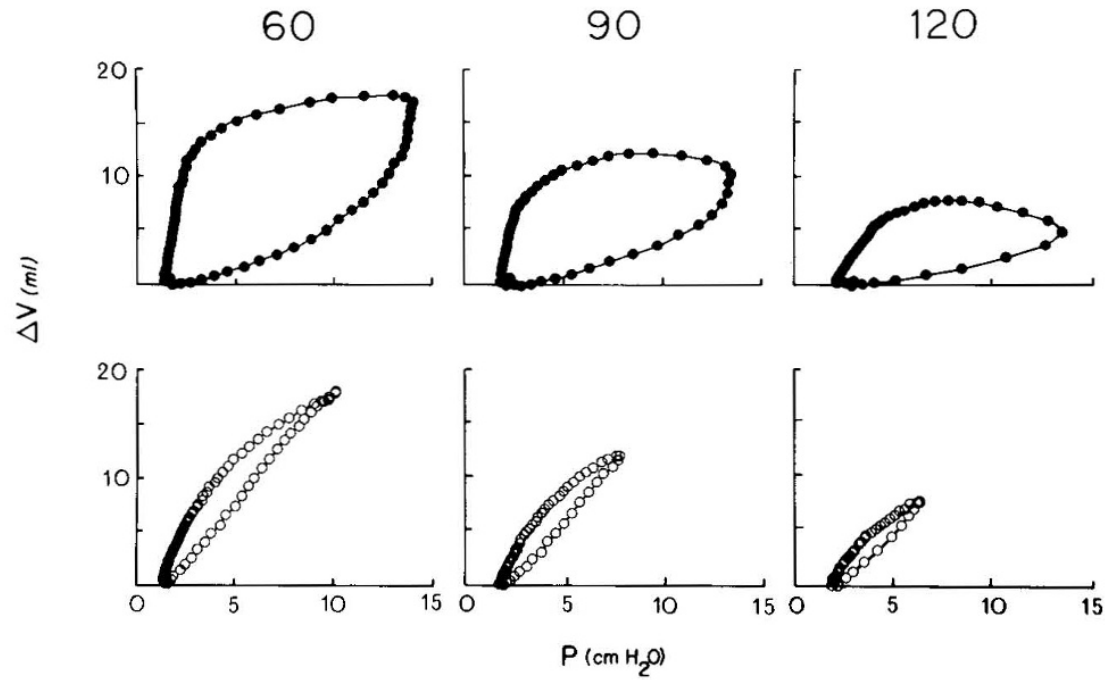

Fig. 3. Dynamic pressure-volume relationships of the respiratory system (closed circles) and the lungs (open circles) obtained in one rabbit at ventilatory rates of 60,90 , and 120 breath $\cdot \mathrm{min}^{-1}$. Interval between points is $0.01 \mathrm{~s}$. Nonlinearity of frictional pressure losses in the endotracheal tube caused a progressive shift of the axis of the pressure-volume loop of the respiratory system, with the highest pressure being in phase with flow. The pressure-volume relationship of the lungs suggests a linear pressure-flow behavior and a higher expiratory than inspiratory resistance.

Table 1. Values of $K_{2}$ of the respiratory system $(R S)$ and endotracheal tube (ETT) in rabbits ventilated at rapid rates*

\begin{tabular}{|c|c|c|c|c|c|c|}
\hline \multirow[b]{2}{*}{ Ventilatory rate } & \multicolumn{3}{|c|}{ Inspiration } & \multicolumn{3}{|c|}{ Expiration } \\
\hline & 60 & 90 & 120 & 60 & 90 & 120 \\
\hline $\begin{array}{l}\mathrm{K}_{2, \mathrm{RS}} \cdot 10^{-3} \\
\mathrm{~K}_{2, \mathrm{ETT}} \cdot 10^{-3}\end{array}$ & $\begin{array}{l}0.29 \pm 0.16 \\
0.19 \pm 0.07\end{array}$ & $\begin{array}{l}0.22 \pm 0.14 \\
0.21 \pm 0.05\end{array}$ & $\begin{array}{l}0.18 \pm 0.11 \\
0.17 \pm 0.09\end{array}$ & $\begin{array}{l}0.37 \pm 0.32 \\
0.30 \pm 0.10\end{array}$ & $\begin{array}{l}0.43 \pm 0.33 \\
0.33 \pm 0.13\end{array}$ & $\begin{array}{l}0.49 \pm 0.37 \\
0.31 \pm 0.13\end{array}$ \\
\hline
\end{tabular}

* Mean $\pm \mathrm{SD}$. Ventilatory rate in breath $\mathrm{min}^{-1} \cdot \mathrm{K}_{2}$ in $\mathrm{cm} \mathrm{H}_{2} \mathrm{O} \cdot \mathrm{ml}^{-2} \cdot \mathrm{s}^{2}$.

Table 2. Inspiratory and expiratory compliances and mean resistances of the respiratory system (RS) and its components: lungs $(L)$, chest wall $(W)$, and endotracheal tube $(E T T)$, at rapid ventilatory rates*

\begin{tabular}{|c|c|c|c|c|c|c|}
\hline \multirow[b]{2}{*}{ Ventilatory rate } & \multicolumn{3}{|c|}{ Inspiration } & \multicolumn{3}{|c|}{ Expiration } \\
\hline & 60 & 90 & 120 & 60 & 90 & 120 \\
\hline $\mathrm{C}_{\mathrm{RS}}$ & $0.58 \pm 0.17$ & $0.51 \pm 0.18$ & $0.48 \pm 0.13 \dagger$ & $0.61 \pm 0.15$ & $0.54 \pm 0.13 \dagger$ & $0.45 \pm 0.12 \dagger \ddagger$ \\
\hline $\mathrm{C}_{\mathrm{L}}$ & $0.88 \pm 0.31$ & $0.74 \pm 0.29 \dagger$ & $0.60 \pm 0.21 \dagger \ddagger$ & $0.96 \pm 0.28$ & $0.77 \pm 0.26 \dagger$ & $0.62 \pm 0.20 \dagger \ddagger$ \\
\hline $\mathrm{C}_{\mathrm{w}}$ & $1.70 \pm 0.58$ & $1.63 \pm 1.00$ & $2.39 \pm 1.08$ & $1.67 \pm 0.69$ & $1.82 \pm 0.68$ & $1.64 \pm 0.99$ \\
\hline$\overline{\mathrm{R}}_{\mathrm{RS}} \cdot 10^{-3}$ & $84.0 \pm 16.5$ & $81.0 \pm 20.9$ & $82.9 \pm 22.4$ & $92.7 \pm 21.1$ & $85.2 \pm 11.8$ & $84.9 \pm 14.4$ \\
\hline$\overline{\mathrm{R}}_{\mathrm{L}} \cdot 10^{-3}$ & $11.1 \pm 6.1$ & $6.5 \pm 3.6 \dagger$ & $5.4 \pm 2.6 \dagger$ & $28.3 \pm 14.3$ & $24.9 \pm 12.4$ & $28.9 \pm 15.9$ \\
\hline$\overline{\mathrm{R}}_{\mathrm{ETT}} \cdot 10^{-3}$ & $72.4 \pm 13.2$ & $73.4 \pm 18.8$ & $76.2 \pm 21.1$ & $57.5 \pm 18.4$ & $60.1 \pm 20.4$ & $55.5 \pm 13.8$ \\
\hline
\end{tabular}

* Compliances in $\mathrm{ml} \cdot \mathrm{cm} \mathrm{H} \mathrm{H}_{2} \mathrm{O}^{-1} \cdot \mathrm{kg}^{-1}$. Resistances in $\mathrm{cm} \mathrm{H}_{2} \mathrm{O} \cdot \mathrm{ml}^{-1} \cdot \mathrm{s}$.

$\dagger \ddagger$ Different from values measured at 60 and 90 breath $\cdot \mathrm{min}^{-1}$, respectively.

Table 3. FRC, tidal volume $\left(V_{\mathrm{T}}\right)$, and mean inspiratory $\left(\overline{\dot{V}}_{\mathrm{I}}\right)$, and expiratory $\left(\overline{\dot{V}}_{\mathrm{E}}\right)$ flows in rabbits ventilated at rapid rates*

\begin{tabular}{lccc}
\hline Ventilatory rate & \multicolumn{1}{c}{60} & \multicolumn{1}{c}{90} & \multicolumn{1}{c}{120} \\
\hline FRC $(n=5)$ & $8.3 \pm 3.1$ & $8.4 \pm 2.5$ & $8.5 \pm 2.9$ \\
$\mathrm{~V}_{\mathrm{T}}$ & $5.3 \pm 0.9$ & $3.4 \pm 0.5 \dagger$ & $2.1 \pm 0.4 \dagger \ddagger$ \\
$\left.\overline{\mathrm{V}}_{\mathrm{I}}\right)$, & $47.2 \pm 8.9$ & $45.4 \pm 11.4$ & $47.5 \pm 9.0$ \\
$\left.\overline{\dot{\mathrm{V}}}_{\mathrm{E}}\right)$, & $23.3 \pm 4.3$ & $22.4 \pm 4.0$ & $16.7 \pm 2.8 \dagger \ddagger$ \\
\hline
\end{tabular}

* Volumes in $\mathrm{ml} \cdot \mathrm{kg}^{-1}$. Flows in $\mathrm{ml} \cdot \mathrm{s}^{-1}$.

$\dagger \ddagger$ Different from values measured at 60 and $90 \mathrm{breath} \cdot \mathrm{min}^{-1}$, respectively.

imate those of human infants $(17,18)$. Although there may be greater differences between healthy rabbits and infants with respiratory failure, our results provide useful insight into the factors that control the delivery and distribution of tidal volume during conventional mechanical ventilation at rapid rates.

Limitations of the method. We used a statistical method to partition pressure losses within the respiratory system into elastic, resistive, and inertial components (equation 1). We assumed that compliance and resistance were independent of lung volume. This assumption was critical in analyzing the effect of ventilatory rate on pulmonary compliance and resistance, since we allowed tidal volume to decrease at the higher ventilatory rates. We showed, however, that the static compliance of the respiratory system (airway occlusions) was independent of lung volume to tidal volumes well above those of the experiment. Because the pressure-flow relationship of the lungs was linear $\left(\mathrm{K}_{2}\right.$ not different from zero), it is unlikely that pulmonary resistance was volumedependent within the range of tidal volume.

The physical meaning of the constants $K_{1}$ and $K_{2}$, which define the resistive pressure losses, may differ from that originally intended by Rohrer when they are applied to the lungs (19). Nonetheless, these constants adequately describe the relationship between resistive pressure losses and gas flow in the endotracheal tube $(8,14)$ and, as demonstrated here, in the total respiratory system. The respiratory system and endotracheal tube had a 
similar value of $K_{2}$. This same value and the good fit for the estimation of pressure drops with the mathematical model indicate that the pressure-flow nonlinearities of both tube and respiratory system were of similar magnitude and in phase with each other and with the gas flow. Although the flow resistance of the chest wall may be nonlinear (20), the contribution of this nonlinearity to the overall pressure-flow behavior of the respiratory system was probably too small to be noticeable. The values of effective pulmonary compliance and resistance obtained with our method are consistent with those previously reported in rabbits $(17,21)$. The inertial coefficients are similar to those predicted by Sullivan et al. (14) and Spells (21) for the endotracheal tube and lungs.

Rate-dependency of pulmonary compliance and resistance. The compliance and resistance of the lungs have been shown to decrease as a function of ventilatory rate in normal subjects $(2,6)$, and especially in subjects with obstructive lung disease $(1,3)$. Such rate-dependency of compliance and resistance may be explained by differences in the distribution of flow caused by either regional heterogeneities within the lungs $(1,4)$ or by the conducting airways acting as a "shunt" compliance in parallel with the peripheral airways (22). Theoretical predictions based on these two models assume a sinusoidal pressure waveform and therefore, need to be modified for mechanically ventilated subjects. In the clinical situation, expiratory time must be lengthened as ventilatory rate is increased in order to avoid gas trapping within the lungs. Inspiration is thus shorter than it would be if the pressure waveform were sinusoidal for the same ventilatory rate. In this respect, an inspiratory time of $0.1 \mathrm{~s}$ at a ventilatory rate of 120 breath $\cdot \mathrm{min}^{-1}$ may be considered equivalent to a ventilatory rate of $300 \mathrm{breath} \cdot \mathrm{min}^{-1}$ with a sinusoidal pattern of flow. This high rate would be within the operative range of the two rate-dependency models for adult human subjects. Given the low compliance and resistance of the peripheral airspaces of the rabbit, however, we would expect the parallel "shunt" mechanism to be unimportant, unless the ventilatory rate were higher or the inspiratory time shorter (22). The rate-dependency of compliance and resistance that we observed would be explained therefore only on the basis of a heterogeneous distribution of flow within the lungs. Experimental evidence obtained during high-frequency oscillation in rabbits supports this view (23).

Differences between inspiratory and expiratory resistance. In addition to its rate dependency, the mean inspiratory resistance of the lungs of the mechanically ventilated rabbits was $18-39 \%$ of the mean expiratory resistance. This large difference contrasts with previous reports in which the inspiratory resistance was 80 $85 \%$ of the expiratory resistance of the airways of spontaneously breathing adult humans and dogs $(7,24,25)$. The larger difference found in the ventilated rabbits may be explained by inspiratory-expiratory differences in the velocity profile of the flow due to the static geometry of the airways (26) and by the greater rate-dependency of inspiratory resistance. More importantly, the higher transpulmonary (and presumably airway transmural) pressure present during inspiration may have distended the conducting airways, thus lowering their resistance (25). Since both inspiratory and expiratory resistance were relatively independent of lung volume, airway distention most likely occurred early in inspiration, with the airways remaining in the flat portion of their pressure-volume relationship until the beginning of expiration $(27,28)$. This behavior is consistent with the concept of the airways as a parallel compartment with an extremely short time constant $(22)$.

Dynamic distention of the airways is limited by bronchomotor tone and by the passive properties of the airway wall and the surrounding parenchymal structures $(28,29)$. During early development bronchomotor tone is decreased and the lung parenchyma is relatively underdeveloped. Therefore, mechanical ventilation with positive pressure may place considerable radial stress on the developing airway during inspiration, even with relatively small tidal volume changes. The effect of radial stress is likely to be greater on the more compliant peripheral airways, where early damage from positive pressure has been described in premature rabbits (30). The difference between mean inspiratory and expiratory pulmonary resistances was greater at the higher ventilatory rates. This larger difference was probably caused, however, by greater rate-dependency of inspiratory resistance, rather than by airway distention. Increasing the ventilatory rate should actually decrease airway distention, since lower tidal volumes (and lower transpulmonary pressures) are needed to achieve the same minute alveolar ventilation at higher ventilatory rates. On the other hand, shear stress on the airway wall may be greater at higher rates because airway volume changes more rapidly.

Dynamic behavior of the endotracheal tube. The pressure-flow behavior of the endotracheal tube in the trachea was relatively independent of both ventilatory rate and flow direction. This is unlike larger endotracheal tubes which show lower inspiratory than expiratory resistance as ventilatory rate is increased due to partial recovery of the dynamic head in the trachea (10). The behavior of the infant-size endotracheal tube can be explained by the presence of turbulent flow and/or a blunt velocity profile throughout the entire length of the tube and the rabbit's trachea. The increased resistance of the tube at the higher ventilatory rates in some of the rabbits is consistent with the velocity profile of the flow in these tubes becoming blunter due to inertial effects as ventilatory rate was increased (5).

Factors affecting delivery of tidal volume. The high resistance and the nonlinearity of the pressure-flow relationship of the respiratory system and endotracheal tube have an important effect on the tidal volume delivered to the lungs at rapid ventilatory rates. Most infant ventilators behave as constant flow generators. The pressure waveform produced by these ventilators approaches a ramp (provided that the flow in the ventilator is high enough to overcome the transient effect of the ventilator's own compliance). We analyzed the effect of the nonlinear mechanics of the respiratory system for this particular case, in which at any point in time $(\mathrm{t}), \Delta \mathrm{P}=\mathrm{a} \cdot \mathrm{t}$, where $\mathrm{a}$ is the slope of the pressure ramp. If we rearrange equation 1 and, for simplicity, ignore the inertial component:

$$
\mathrm{K}_{2} \cdot \dot{\mathrm{V}}^{2}+\mathrm{K}_{1} \cdot \dot{\mathrm{V}}-(\mathrm{a} \cdot \mathrm{t}-\Delta \mathrm{V} / \mathrm{C})=0
$$

The solution of this quadratic equation for $\dot{V}>0$ is:

$$
\dot{\mathrm{V}}=\frac{-\mathrm{K}_{1}+\left[\mathrm{K}_{1}{ }^{2}+4 \cdot \mathrm{K}_{2} \cdot(\mathrm{a} \cdot \mathrm{t}-\Delta \mathrm{V} / \mathrm{C})\right]^{1 / 2}}{2 \cdot \mathrm{K}_{2}}
$$

where

$$
\Delta \mathrm{V}=\int_{\mathrm{t}=0}^{\mathrm{t}} \dot{\mathrm{V}} \cdot \mathrm{dt}
$$

Equation 5 is implicit in $\dot{V}$, and must be solved with an iterative computer analysis. We predicted with such an analysis that, as the inspiratory time is shortened, the high inspiratory resistance of the respiratory system prevents the gas flow from reaching a constant value (Fig. 4), as it would occur if the resistance were lower or the inspiratory time were longer (31). As a consequence, tidal volume depends progressively less on the effective compliance of the respiratory system as ventilatory rate is increased. In addition, the nonlinearity of the resistive pressure-flow relationship of the respiratory system has an important effect on tidal volume at these rates (Fig. 4). The iterative analysis of equations 5 and 6 predicted tidal volumes of $4.6,3.2$, and $2.2 \mathrm{ml} \cdot \mathrm{kg}^{-1}$ at ventilatory rates of 60,90 , and $120 \mathrm{breath} \cdot \mathrm{min}^{-1}$, similar to the tidal volumes of $5.3,3.4$, and $2.1 \mathrm{ml} \cdot \mathrm{kg}^{-1}$ which we observed. Tidal volume was underestimated at a ventilatory rate of 60 breath $\cdot \mathrm{min}^{-1}$, probably because the lower flow in the ventilator produced a gradual increase in the slope of the pressure wave rather than a pressure ramp at this ventilatory rate. 


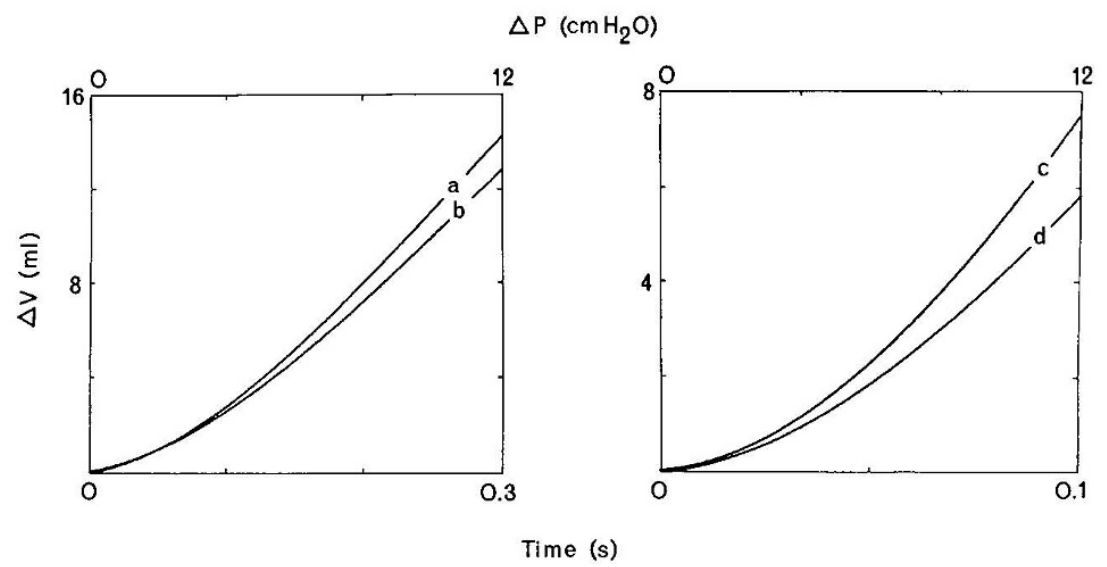

Fig. 4. Predicted time course of changes in lung volume $(\Delta \mathrm{V})$ when a pressure ramp is applied to the respiratory system. The slope of the ramp was modified to achieve the same maximal change in pressure $(\Delta \mathrm{P})$ for an inspiratory time of 0.3 (left) and $0.1 \mathrm{~s}$ (right). Respiratory system compliance $\left(1.8 \mathrm{ml} \cdot \mathrm{cm} \mathrm{H}_{2} \mathrm{O}^{-1}\right)$ and $\mathrm{K}_{1}\left(60 \cdot 10^{-3} \mathrm{~cm} \mathrm{H}_{2} \cdot \mathrm{ml}^{-1} \cdot \mathrm{s}\right)$ were the same in all cases. $\mathrm{K}_{2}$ was 0 in $a$ and $c$, and $0.3 \cdot 10^{-3} \mathrm{~cm} \mathrm{H}_{2} \mathrm{O} \cdot \mathrm{ml}^{-2} \cdot \mathrm{s}^{2}$ in $b$ and $d$. Nonlinearity of the pressure-flow relationship of the respiratory system decreased tidal volume by 10 and $21 \%$ with inspiratory times of 0.3 and $0.1 \mathrm{~s}$, respectively.

\section{SUMMARY}

Although there are obvious histological differences between the lungs of healthy rabbits and those of human infants with respiratory failure, the same mechanical principles determine flow distribution in both rabbits and infants. Some degree of rate-dependency of flow distribution can therefore be expected in the lungs of infants undergoing mechanical ventilation, particularly in those with heterogeneous distribution of airway resistance (e.g. meconium aspiration). In such cases, increasing the ventilatory rate (or shortening the inspiratory time) may be beneficial by redistributing the tidal volume to areas of normal resistance, which are less susceptible to barotrauma (32). Increasing the ventilatory rate, on the other hand, markedly decreases the tidal volume because of the high resistance and the nonlinearity of the pressure-flow relationship of the respiratory system. The effect of the nonlinear resistance is greater as the slope of pressure developed by the ventilator increases, and greatest when the pressure waveform is sinusoidal (see equation 7, Ref. 1). Very high ventilatory flows should therefore be avoided at rapid ventilatory rates. At these rates, tidal volume may be increased, and the working range of the ventilator extended (33), by simply increasing the diameter or decreasing the length of the endotracheal tube, or, alternatively, by decreasing the density of the inspiratory gas.

\section{REFERENCES}

1. Otis AB, McKerrow CB, Bartlett RA, Mead J, Mcllroy MB, Selverstone NJ, Radford EP 1956 Mechanical factors in distribution of pulmonary ventilation. J Appl Physiol 8:427-443

2. Albright $\mathrm{CD}$, Bondurant $\mathrm{S}$. Some effects of respiratory frequency on pulmonary mechanics. J Clin Invest 44:1362-1370

3. Grimby G, Takishima T, Graham W, Macklem P, Mead J 1968 Frequency dependence of flow resistance in patients with obstructive lung disease. J Clin Invest 47:1455-1465

4. Hogg JC, Macklem PT, Thurlbeck WM 1969 The resistance of collateral channels in excised human lungs. $J$ Clin Invest 48:421-431

5. Finucane KE, Dawson SV, Phelan PD, Mead J 1975 Resistance of intrathoracic airways of healthy subjects during periodic flow. J Appl Physiol 38:517-530

6. Hedenstierna $G 1976$ The effect of respiratory frequency on pulmonary function during artificial ventilation. Acta Anaesthesiol Scand 20:20-31

7. Miller TK, Pimmel RL 1982 Forced noise mechanical parameters during inspiration and expiration. J Appl Physiol 52:1530-1534

8. Pérez Fontán JJ, Heldt GP, Gregory GA 1985 The effect of a gas leak around the endotracheal tube on the mean tracheal pressure during mechanical ventilation. Am Rev Respir Dis 132:339-342

9. Bland RD, Kim MH, Light MJ, Woodson JL 1980 High frequency mechanical ventilation in severe hyaline membrane disease. An alternative treatment?

\section{Crit Care Med 8:275-280}

10. Chang HK, Mortola JP 1981 Fluid dynamic factors in tracheal pressure measurement. J Appl Physiol 51:218-225

11. Baydur A, Behrakis PK, Zin WA, Jaeger M, Milic-Emili J 1982 A simple method for assessing the validity of the esophageal balloon technique. Am Rev Respir Dis 126:788-791.

12. Heldt GP, Peters RM 1978 A simplified method to determine functional residual capacity during mechanical ventilation. Chest 74:492-496

13. Roy R, Powers SR, Kimball WR 1974 Estimation of respiratory parameters by the method of covariance ratios. Computers Biomed Res 7:21-39

14. Sullivan M, Paliotta J, Saklad M 1976 Endotracheal tube as a factor in measurement of respiratory mechanics. J Appl Physiol 41:590-592

15. Grimby G, Hedenstierna G, Löfstrom B 1975 Chest wall mechanics during artificial ventilation. J Appl Physiol 38:576-580

16. Zar JH 1974 Biostatistical Analysis. Prentice Hall, Englewood Cliffs, NJ

17. Crossfill ML, Widdicombe JG 1961 Physical characteristics of the chest and lungs and the work of breathing in different mammalian species. J Physiol (Lond) 158:1-14

18. Butz RO 1968 Length and cross-section growth patterns in the human trachea. Pediatrics 42:336-341

19. Mcllroy MB, Mead J, Selverstone NJ, Radford EP 1955 Measurement of lung tissue viscous resistance using gases of equal kinematic viscosity. $\mathrm{J}$ Appl Physiol 7:485-490

20. Gottfried SB, Rossi A, Calverley PMA, Zocchi L, Milic-Emili J 1984 Interrupter technique for measurement of respiratory mechanics in anesthetized cats. J Appl Physiol 56:681-690

21. Spells KE 1969/70 Comparative studies in lung mechanics based on a survey of literature data. Respir Physiol 8:37-57

22. Mead J 1969 Contribution of compliance of airways to frequency-dependent behavior of lungs. J Appl Physiol 26:670-673

23. Watson JW, Jackson $\mathrm{AC} 1984 \mathrm{CO}_{2}$ elimination as a function of frequency and tidal volume in rabbits during HFO. J Appl Physiol 57:354-359

24. Hyatt RE, Wilcox RE 1963 The pressure-flow relationships of the intrathoracic airway in man. J Clin Invest 42:29-39

25. Ferris BG, Mead J, Opie LH 1964 Partitioning of respiratory flow resistance in man. J Appl Physiol 19:653-658

26. Clarke SW, Jones JG, Oliver DR 1972 Factors affecting airflow through branched tubes. Bull PhysioPathol Respir 8:409-428

27. Bhutani VK, Rubenstein SD, Shaffer TH 1981 Pressure-volume relationships of tracheae in fetal newborn and adult rabbits. Respir Physiol 43:221-231

28. Hahn HL, Graf PD, Nadel JA 1976 Effect of vagal tone on airway diameters and on lung volume in anesthetized dogs. $\mathbf{J}$ Appl Physiol 41:581-589

29. Nakamura M, Luchtel DL, Ikeda Y, Sasaki H, Okubo T, Takishima $T$, Hildebrandt J 1984 Surrounding structures affect pressure-diameter behavior of excised dog bronchi. J Appl Physiol 57:1632-1639

30. Nilsson R, Grossmann G, Robertson B 1980 Pathogenesis of neonatal lung lesions induced by artificial ventilation: evidence against the role of barotrauma. Respiration 40:218-225

31. Bates JHT, Rossi A, Milic-Emili J 1985 Analysis of the behavior of the respiratory system with constant inspiratory flow. J Appl Physiol 58:18401848

32. Reynolds EOR 1979 Ventilator therapy. In: Thibeault DW, Gregory GA (eds) Neonatal Pulmonary Care. Addison-Wesley, Menlo Park, CA pp 217-236

33. Boros SJ, Bing DR, Mammel MC, Hagen E, Gordon MJ 1984 Using conventional infant ventilators at unconventional rates. Pediatrics 74:487-492. 